\title{
Pitfalls come to light
}

\section{Berkeley}

THE application of DNA fingerprinting to forensic samples is gaining rapid acceptance in the US criminal court system. In less than two years, DNA data have been considered as evidence in more than 80 criminal rape and murder trials in 27 states, leading to at least 64 convictions or pleas of guilty by the defendants. But some biologists and legal experts have expressed concern that the evidence is not as infallible as judges and juries are being led to believe.

The power of the technique is not in dispute. When performed correctly, it can match DNA from an individual to that extracted from samples of blood, hair or semen left at the scene of a crime. The most commonly used method relies on restriction fragment length polymorphisms (RFLPs), regions of DNA that vary among individuals, producing fragments of different sizes when the DNA is cut with restriction enzymes and run on sizing gels. When probes for a large enough number of RFLPs are used, the likelihood of a match between two unrelated individuals may be less than 1 in 100 million.

Forensic DNA testing is at present carried out by three commercial US laboratories, and the Federal Bureau of Investigation (FBI).

Concern about the tests focuses on the potential for human error in sample treatment or data analysis, the interpretation of DNA patterns, the uniformity of criteria used to determine whether two samples match and the population studies on which the predicted likelihood of a mismatch is based.

In written testimony presented to Congress during hearings on DNA fingerprinting in March, law professor Barry Scheck, a member of the New York Governor's Commission on Forensic DNA Typing, writes that in many of the court cases there has been "little, if any, informed cross examination of private

\section{RESIGNATION}

\section{Koop out early}

\begin{abstract}
Washington
US SuRgeon General C. Everett Koop announced last week that he is resigning with effect from July. He indicated in February that he did not intend to serve out his term, which would have expired in November. Koop took an unexpectedly high profile position on AIDS and the need for education in AIDS prevention during a time when others in the Reagan administration had little to say about the disease. Koop also worked hard to reduce the incidence of smoking in the United States.
\end{abstract}

Joseph Paica
DNA vendors, and few qualified expert witnesses testifying in opposition. The defence lawyers in these cases ... have been overwhelmed."

That trend may be changing, as the defence in a murder case now under way in the Bronx has lined up an impressive string of biologists to testify to the potential weaknesses in the analysis of DNA extracted from a blood spot on the defendant's watch. The witnesses included human geneticists Eric Lander and David Page of the Whitehead Institute, Conrad Gilliam of Columbia University and Howard Cooke of the Medical Research Council in Edinburgh.

Among the issues raised in the case was the lack of adequate controls in the DNA analysis performed by Lifecodes Corporation, a New York company specializing in DNA fingerprinting. Lander challenged Lifecodes' decision to discount two nonmatching bands as contaminants, even though no experiment had shown that the bands were not actual human DNA differences. In addition, Lander questioned the company's conclusion that the blood on the watch came from a female, based on a sex-determination test performed with a male-specific probe. The autoradiogram used to make the DNA fingerprint contained no positive control to show that the probe was functioning properly, and Lifecodes scientist Michael Baird testified that the autoradiogram could nevertheless be interpreted in the absence of a positive control.

Cooke, who developed two of the probes used by Lifecodes in the DNA analysis, questioned whether one could match samples with certainty by eye, because variants in the population often produce DNA fragments of similar sizes. In traditional DNA diagnostics used in prenatal screening, the parents' DNA provides at most four separate bands with which the child's DNA must be judged to match or not, Cooke says. But forensic use involves much more variability, and therefore demands well-defined standards for determining a match.

The strength of DNA fingerprinting data lies in the potentially low probability of a match occurring between two unrelated samples. But Lander warns of a potential error that could arise in the reporting of those probabilities, if standards for a match are not uniform. The stringency of the standards for what constitutes a match determines the number of identifiably distinct variants of a given RFLP that exist in the population, and that, in turn affects the probability that a match might occur at random.

On the basis of both Lifecodes' testimony in court and unpublished scientific papers introduced into evidence, Lander testified that a less stringent matching rule was used to determine whether one forensic sample matched another than the rule used to determine the probability that such a match could occur at random. The result, according to Lander, could be an understatement by a factor of 20 of the actual frequency that a match might occur at random for a given RFLP. If this were to occur for each of the RFLPs in a case, he says, the total probability could be understated by a factor of 1,000 or more.

There is no set of guidelines to help individual testing laboratories to make decisions about matching criteria and other procedures, nor is there a standard proficiency testing or licensing process for laboratories that perform the DNA analysis.

An independently conducted blind trial of commercial laboratories was carried out in 1987 by the California Association of Crime Laboratory Directors. Although the laboratories knew they were under investigation, a worrying number of errors was revealed.

Fifty samples, including semen stains, blood stains and hair were sent to the three commercial US testing laboratories. Two of the laboratories mistakenly matched unrelated samples. Both laboratories say they have identified the source of the problem, in one case non-binding of DNA to a filter, and in the other the accidental mixing of two samples. While measures have been taken to avoid such mistakes in the future, the blind trial points out the possibility of human error.

John Huss, vice-president of Cellmark Diagnostics, a Maryland subsidiary of Imperial Chemical Industries, and the company that accidentally mixed two samples, says the error led the company to take on additional quality control measures. Operations are now observed by a second technician, he says, and the observations recorded in a company log book.

Nevertheless, as caseloads grow, pressure on the private companies is intense, and could lead to errors, warned Cooke. That pressure may eventually diminish, as state and local crime bureaus set up their own laboratories.

US Representative Don Edwards, who chaired the congressional hearing on DNA fingerprinting, has called for licensing and regular proficiency testing of private laboratories and state and local criminal laboratories that perform the tests. A National Academy of Sciences study that was likely to have provided recommendations for standards of data analysis was recently postponed last year when neither the FBI nor the National Institute of Justice could provide funding. A report on DNA fingerprinting by the Congressional Office of Technology Assessment is due out by the end of the year. Although it will make no recommendations, it may provide the information Congress needs to design regulatory legislation. Marcia Barinaga 